\title{
La industria automotriz y el fomento a las cadenas productivas en Sonora: el caso de la Ford en Hermosillo' 1
}

\section{The automotive industry and the support to productive chains in Sonora: the Ford case in Hermosillo}

\author{
Fabiola Galicia-Bretón Mora \\ ISAAC LEObARdo SÁNCHEZ-JUÁREZ*
}

\begin{abstract}
The formation of productive chains is an indispensable condition for local economic development in the new scenario generated by a globally competitive environment. In the case of Sonora, from the establishment of the Ford Motor Company stamping and assembly factory in Hermosillo in 1986, the local enterprises have not been able to fully integrate into the productive processes of the factory. This failure has its main origin in the inadequate industrial policy applied by governmental and private organisms, together with the lack of an entrepreneurial culture that takes up higher risks. In this article we present the history of automotive industry in Mexico, specially in the case of Sonora. The results allow foreseeing that it is unlikely that-in the short term-productive chains will be produced.
\end{abstract}

Keywords: productive chains, automotive industry, Ford-Hermosillo, industrial policy.

\section{Resumen}

La formación de cadenas productivas es una condición indispensable para el desarrollo económico local en el nuevo escenario que genera un entorno globalmente competitivo. En el caso de Sonora, a partir de la instalación de la planta de estampado y ensamble de la Ford Motor Company en Hermosillo en 1986, las empresas locales no han podido integrarse plenamente a los procesos productivos de la planta. Este fracaso tiene su principal origen en la inadecuada política industrial aplicada por los organismos gubernamentales y privados, junto con la falta de una cultura emprendedora que asuma mayores riesgos. En este artículo se presenta la historia de la industria automotriz en México, en especial el caso de Sonora. Los resultados permiten prever que difícilmente -en el corto plazose generarán encadenamientos productivos.

Palabras clave: cadenas productivas, industria automotriz, Ford-Hermosillo, política industrial.

${ }^{1}$ Los autores agradecen las sugerencias de los dictaminadores anónimos.

* El Colegio de la Frontera Norte, México. Correos-e: fgalicia@colef.mx, isaac@colef.mx. También la autora agradece a la Mtra. Lorenia Velázquez Contreras y a El Colegio de Sonora el apoyo para la culminación de su tesis de maestría. 


\section{Introducción}

En el ámbito mundial, el fenómeno de globalización ha generado un aumento en la competencia e interdependencia entre empresas y países. Como consecuencia de ello, durante los últimos 20 años los países en vías de desarrollo han adoptado políticas de liberalización económica, muchas de ellas utilizando las exportaciones como estrategia principal de desarrollo. Debido a esto y dada la necesidad de aumentar la productividad y competitividad de su base industrial local, han intentado fomentar el desarrollo de nuevos modelos de producción. En este sentido, las cadenas productivas han servido de apoyo para que las empresas locales se conecten con empresas trasnacionales y logren aumentar sus niveles productivos.

Para lograrlo es necesario contar con una política industrial que fomente el desarrollo de la industria local, junto con un enfoque dirigido a potenciar las ventajas competitivas de la región. En el caso de México, actualmente las empresas nacionales tienen escasos lazos productivos con las de origen extranjero, lo que se refleja en un bajo contenido de insumos locales en los productos manufacturados que se destinan a la exportación, un claro ejemplo es el de la industria automotriz. Esto ha puesto de manifiesto que utilizar políticas centralizadas y dirigidas a apoyar a la gran empresa no ha funcionado, por lo que surge la necesidad de darle un nuevo enfoque a las políticas de fomento industrial y a la manera de interactuar de los organismos que intervienen en la formulación de éstas.

$\mathrm{Al}$ respecto, Wong (1999) señala que las transformaciones en la manera de operar de la economía en su conjunto, han demandado nuevas funciones para las entidades locales y regionales, por lo que se debe crear una base que sustente las nuevas relaciones entre todos los niveles de gobierno. De igual manera, para Ybarra (1998) el enfoque de las políticas de fomento industrial ha tenido que cambiar: ahora necesita ser de carácter más regional y dirigirse a las micro, pequeñas y medianas empresas para lograr un mayor efecto en la economía local.

En el caso de Sonora, el origen de la industria automotriz se remonta al año 1986, cuando la Ford Motor Company (FMC) instaló en la ciudad de Hermosillo una planta de estampado y ensamble. Esta firma es representativa de la problemática de industrialización nacional, ya que a más de dos décadas de su instalación persiste una baja participación del empresariado local en el proceso productivo, lo que hace necesario contar con una política industrial en la que, de manera coordinada, las instituciones gubernamentales y privadas apoyen a los proveedores potenciales locales, sobre todo en lo que se refiere al aumento de su competitividad y productividad, para que se pueda conformar una cadena de proveedores especializada en la región 
Con la ampliación de la planta de Hermosillo en el año 2005, así como la instalación en el estado de un grupo de nuevos proveedores, se presenta otra oportunidad para los actores económicos locales (empresarios e instituciones gubernamentales y privadas) de integrarse en los procesos productivos de la planta y sus proveedores.

La tesis que sostiene esta investigación surge de la propuesta de Porter (1991), quien indica que la participación del gobierno, en la elaboración de políticas de fomento industrial, debe crear las condiciones para que las empresas locales innoven y aumenten su ventaja nacional. De esta manera, se considera que a partir de los ańos ochenta, el enfoque de las políticas federales y estatales de fomento industrial se dirigió exclusivamente a apoyar a la gran industria trasnacional, dejando fuera a las empresas locales, ${ }^{2}$ lo que a la postre evitó la formación de encadenamientos productivos locales alrededor de la industria automotriz en el estado de Sonora. Lo que se pretende demostrar con este artículo son las fallas que han tenido los organismos gubernamentales y privados para conformar una cadena productiva a partir de la instalación de la FMC en Hermosillo, Sonora.

El documento se divide en cuatro partes: en la primera se describe la historia de la industria automotriz en México; en la segunda se narra la forma en que se constituyó la industria del automóvil en Sonora, a partir de la instalación de la planta de ensamble y estampado de la FMC, así como su más reciente ampliación; en la tercera parte se presenta la metodología de la investigación, los actores involucrados y las herramientas utilizadas para contrastar la hipótesis, y en la cuarta se presentan los resultados agrupados en torno a emisores y receptores de la política industrial para la formación de cadenas productivas locales. ${ }^{3}$

\section{La industria automotriz en México}

La historia de la industria automotriz en México tiene su origen en 1925, cuando FMC instaló la primera planta de montaje en la ciudad de México; sin embargo, esta industria se comenzó a regular hasta el año 1947, cuando el gobierno estableció un sistema de cuotas de importación para graduar la incorporación de autopartes fabricadas en México. El año de 1962 se considera el comienzo del desarrollo contemporáneo de la industria automotriz, en ese año se emitió el Decreto de Integración de la Industria Automotriz, como parte de la estrategia del modelo de sustitución de

${ }^{2}$ Vázquez y Hernández (2008) demuestran que en los años sesenta, el gobierno del estado intentó fomentar las cadenas productivas locales; sin embargo, se enfrentó a una clase empresarial que tenía una aversión al riesgo y que, por tanto, resultaba poco emprendedora.

${ }^{3} \mathrm{El}$ marco conceptual lo constituye la literatura acerca de las cadenas productivas. Para el lector interesado en los referentes teóricos de la investigación se recomienda la lectura de Porter (1991), Gereffi et al. (1994) y Gereffi $(1995,2002)$. 
importaciones (MSI). En dicho decreto se estipuló que a partir del 1 de septiembre de 1964, el contenido de piezas de fabricación nacional en el ensamble de los vehículos debía ser de $60 \%$ sobre los costos directos de producción, además se prohibió la importación de vehículos ensamblados y se restringió el uso de materias primas de origen extranjero, sometiéndolas a permisos de importación (Fimbres, 1984; Zapata, 2005).

Con la puesta en marcha de este decreto aumentaron los niveles de empleo, el valor de la producción, la inversión y los salarios; también se generó una entrada selectiva de nuevas empresas que dejó fuera de la competencia a las que no tenían acceso al capital, tecnología y know-how, aunado a lo reducido que era el mercado por aquellos ańos; por lo que al final la industria automotriz en México se convirtió en un oligopolio. Otro de los problemas que surgieron con dicho decreto fue el aumento de las importaciones, debido al crecimiento del volumen de la producción, lo que se reflejó en el déficit de la balanza comercial del sector.

A raíz de estos problemas, en 1969 se emitió un nuevo decreto con el que se buscó expandir el mercado interno y establecer un sistema de compensación de importaciones por exportaciones, por lo que estas últimas se consideraron un medio para resolver el desequilibrio de la balanza comercial automotriz. Debido a que los problemas en la balanza comercial no se solucionaron, en 1972 se emitió otro decreto en el que se proponía que el capital mexicano debía participar con $60 \%$ en la constitución de nuevas empresas.

Los problemas en la balanza comercial del sector automotriz no se solucionaron (cuadro 1), por lo que el gobierno intervino y en junio de 1977 emitió el Decreto para el Fomento de la Industria Automotriz, donde ya se fijaron las bases del cambio en la orientación a la exportación. Lo que se buscó con este nuevo decreto fue aumentar el nivel de productividad del sector y que las empresas racionalizaran el uso de divisas para equilibrar la balanza de pagos (Carrillo, 1990).

Por otro lado, en los años setenta en Estados Unidos comenzó una crisis en la industria automotriz que presentó sus años más críticos entre 1980 y 1982, que coincidió con el estancamiento del capital productivo en el ámbito mundial. Esta crisis obedeció a la desaceleración del ciclo de acumulación del capital productivo en la industria, lo que generó un descenso en la tasa media de ganancia de las tres más grandes empresas automotrices estadounidenses: General Motors (GM), FMC y Chrysler (CHR) (Sandoval, 1987).

Para enfrentar dicha crisis, las trasnacionales automotrices llevaron a cabo diversas acciones, entre ellas: generar capacidades de internacionalización productiva y comercial, por medio del traslado de armadoras a 


\section{Cuadro 1 \\ Comercio exterior de la industria del automóvil (millones de dólares)}

\begin{tabular}{lrrr}
\hline & 1970 & \multicolumn{1}{c}{1975} & \multicolumn{1}{c}{1981} \\
\hline 1. Exportaciones & 26.8 & 122 & 377.8 \\
Vehículos de pasajeros & 0.0 & 4.7 & 70 \\
Pick-Ups, camiones y tractocamiones & 0.4 & 4 & 39.5 \\
Partes de motor para vehículos & 26.4 & 55.3 & 165 \\
Chasises & - & 1.9 & 1.5 \\
Motores & - & 35.4 & 61.5 \\
Sistemas de amortizamiento y suspensiones & - & 11.6 & 18.4 \\
Partes de motor & - & 9.1 & 21.9 \\
2. Importaciones & 256.7 & 750.3 & 2265.2 \\
3. Balanza comercial & -229.8 & -628.3 & -1887.4 \\
\hline
\end{tabular}

Fuente: Elaborado a partir de Ramírez y González-Aréchiga (1993).

regiones geográficas cercanas a los mercados mundiales; $y$, a partir de 1983, asociaciones de capitales entre firmas estadounidenses y japonesas.

En lo que se refiere al traslado de armadoras a otras regiones, las llamadas tres grandes (GM, FMC y CHR) consideraron promover mayores relaciones con algunos países periféricos, entre ellos Corea, Taiwán, España, Brasil y México; los cuales presentaban estructuras de costos sumamente bajos y ofrecían ventajas fiscales favorables para dichas corporaciones. En sus estrategias de relocalización, México se presentó como una de las opciones más atractivas para ser utilizada en el corto plazo como plataforma de exportación y enfrentar la competencia en Estados Unidos.

Como resultado de lo anterior, en el país se instaló la planta de ensamble y motores de GM en el complejo de Ramos Arizpe, Coahuila, en 1981, que en su momento representó la inversión más grande de esta corporación en toda América Latina. La planta de motores de CHR, también en Ramos Arizpe, y la planta de motores de FMC en Chihuahua en 1983 (Vicencio, 2007).

Al mismo tiempo, en México comenzaron a gestarse cambios económicos, políticos y sociales. En materia de política económica, el gobierno federal renovó sus programas oficiales con base en dos elementos: estabilidad monetaria (o de precios) y apertura externa. En lo que se refiere a la apertura externa, el gobierno federal introdujo cambios orientados a modificar sus pautas de crecimiento, desplazando el centro de gravedad de las exportaciones primarias y del petróleo a las manufactureras, conformando un nuevo patrón de desarrollo en el que se impulsaron sectores estratégicos, como la industria de transformación.

En el Plan Nacional de Desarrollo 1983-1988 se estableció como propósito central el fomento y ampliación de las exportaciones de productos manufacturados no petroleros, dicho propósito se definió en el 
Programa Nacional de Fomento Industrial y Comercio Exterior 19841988 (Pronafice) (peF, 1983; Secofi, 1984).

En el año 1983 el gobierno intervino otra vez en la industria automotriz: en septiembre emitió el Decreto para la Racionalización de la Industria Automotriz, con el que se reforzaron las medidas del decreto emitido en 1977 en torno al equilibrio de la balanza de pagos y la consolidación de la integración de partes nacionales; las nuevas propuestas de este decreto fueron alcanzar mayores economías de escala mediante el aprovechamiento de los mercados internos y externos, la reducción del número de líneas y modelos, la estandarización de partes y componentes, y el fomento de desarrollo tecnológico y nuevas líneas de producción (Fimbres, 1984; Ramírez y González-Aréchiga, 1993). ${ }^{4}$

Es en este nuevo patrón de desarrollo económico del país en los años ochenta, que la industria automotriz se convirtió en factor fundamental de apertura externa y reconversión industrial. Los planes de desarrollo se enfocaron a captar inversión extranjera directa (IED) y dar libertad a los estados para atraer inversiones a su territorio, sin necesidad de permiso federal. Fue entonces cuando en Sonora apareció FMC como una alternativa viable para fortalecer el sector exportador, enfrentar las necesidades de inversión productiva, generar empleos y captar divisas. Así, Sonora se incorporó al propósito del gobierno federal en sus esfuerzos de reconversión industrial y tecnológica por la vía de un modelo exógeno.

\section{La industria automotriz en Sonora: planta de estampado y ensamble de la FMC}

En 1986, en la ciudad de Hermosillo se instaló la planta de estampado y ensamble propiedad de FMC, como respuesta a las necesidades tanto de la trasnacional como las del gobierno mexicano. Dicha empresa necesitaba reducir costos y aumentar utilidades, por lo que implementó nuevos modos de organización, producción y localización. El gobierno, por su parte, buscaba salir de la crisis económica y darle un cambio estructural a la política económica, por lo que un elemento fundamental de su política industrial fue la inversión extranjera dirigida a la exportación de manufacturas.

La historia de la planta de estampado y ensamblado de Hermosillo comenzó a finales de 1983, cuando la trasnacional empezó a estudiar la

\footnotetext{
${ }^{4}$ Carrillo (1997) se presenta un análisis completo de las maquiladoras automotrices localizadas en la frontera norte de México. Se concentra en explicar la política dirigida a ellas y sus características entre 1965 y 1997, usando como ejemplo el caso de Delphi. Concluye que las empresas maquiladoras evolucionan de acuerdo, al menos, con tres instancias: su trayectoria organizacional, las estrategias corporativas de las firmas involucradas y el sector productivo de pertenencia.
} 
posibilidad de instalarse en dicha ciudad. Meses después, en enero de 1984, se publicó en The Wall Street Journal que en Hermosillo se instalaría la planta, ganándole a otras plazas como Taiwán, Canadá, Portugal, Chihuahua, Ciudad Juárez, Matamoros y Nuevo Laredo. La decisión se tomó, entre otras razones, por las concesiones otorgadas por los gobiernos estatal y municipal, la ubicación geográfica que se traduciría en disminución de costos de transportación tanto de materias primas como del producto terminado, la oferta de instituciones educativas capaces de preparar al personal que laboraría en la planta y una abundante mano de obra barata. Todos estos factores sirvieron para considerar a la entidad una plataforma ideal de exportación (Fimbres, 1984; Sandoval, 1987).

Como se señaló, la instalación de la planta en Hermosillo respondió sobre todo a la necesidad de la trasnacional por encontrar nuevas estrategias para competir en el mercado estadounidense. Originalmente esta planta estaba ubicada en la ciudad de Fremont, en California, y se trasladó a Hermosillo debido al problema con la Union of American Workers, que se opuso a la automatización de la planta, para incrementar la aplicación de tecnologías flexibles en su proceso productivo y así reducir costos, necesarios para competir internacionalmente (Ramírez y GonzálezAréchiga, 1993).

En enero de 1984, FMC anunció una alianza tecnológica y comercial con Koyo Kogyo (Mazda), empresa japonesa que le permitiría disminuir sus pérdidas derivadas de sus bajas ventas y se repartiría oligopólicamente el mercado automotriz de autos compactos. Estas dos empresas participaron en el proyecto de la planta de Hermosillo: la inversión inicial fue de alrededor de 500 millones de dólares y se planeó producir cada año 130,000 autos subcompactos de cuatro cilindros, destinados al mercado estadounidense. Las operaciones de la planta comenzaron formalmente en noviembre de 1986 (Maldonado, 1995; Fimbres, 1984; Sandoval, 2003).

Junto con la ensambladora, en el parque industrial de Hermosillo se instaló un grupo de empresas proveedoras satélite o de responsabilidad total, debido, entre otras causas, al principio justo a tiempo/control total de calidad (JIT/TQC) que se desarrollaría en la planta, y el cual demandaba cierta coordinación entre proveedores y ensambladora; otra causa obedeció a que el tipo de vehículo que se fabricaría en Hermosillo estaría principalmente dirigido al mercado externo, y se tenía que responder a las exigencias de calidad de los mercados internacionales, lo que implicaba la demanda de componentes que no se producían en Sonora (cuadro 2).

Con la instalación de la planta de FMC en Hermosillo se hizo evidente la relación desigual entre los gobiernos federal y estatal con el sector productivo de la entidad: se observó un mayor peso en sus apoyos a las exigencias de FMC y se dejaron en segundo plano las demandas de los 
Cuadro 2

Proveedores de FMC en Sonora, 1986

\begin{tabular}{lllrr}
\hline & \multicolumn{1}{c}{ Nombre } & \multicolumn{1}{c}{ Producto } & Inversión $^{a}$ & Empleos \\
\hline 1 & Carplastic & Partes de plástico & 600 & 100 \\
2 & Cisa & Asientos & 4,420 & 650 \\
3 & Cima & Alfombras & 473.2 & 80 \\
4 & Pemsa & Cinturones de seguridad & 481 & 130 \\
5 & Aurolin & Pinturas & 676 & 36 \\
6 & Goodyear & Llantas & 260 & 15 \\
7 & Pittsburgh & Pinturas & 1,000 & n.d. \\
\hline
\end{tabular}

${ }^{a}$ Millones de pesos.

Fuente: Elaborado a partir de Sandoval (1987).

industriales locales. Un ejemplo de ello fue el apoyo que se dio a la trasnacional, aprovechando el decreto de 1983 que permitía una participación menor a $60 \%$ de autopartes nacionales cuando la producción se destinaba a la exportación; se respaldó a la trasnacional para importar 100\% de su tecnología y funcionar hasta con $70 \%$ de partes y componentes importados y sólo $30 \%$ de insumo nacional, lo mismo sucedió con sus proveedores instalados en el estado. El resultado fue una escasa integración de la economía local al proceso productivo de la planta. Todavía en los años noventa era clara la baja integración de productos nacionales en esta planta, lo que confirma que no se logró generar un encadenamiento productivo con los proveedores de materia prima de la región (Sandoval, 1987; Carrillo, 2003; Maldonado, 1995).

Muchas fueron las causas de la escasa participación del empresariado local en el proceso productivo de la trasnacional y sus proveedores. Una de ellas fue el enfoque de los programas gubernamentales, ya que fue hasta el Plan Nacional de Desarrollo 1995-2000, y en específico el Programa de Política Industrial y Comercio Exterior 1996-2000, que se comenzó a tomar en cuenta al microempresario y reconocer que en el ámbito nacional formaban un número considerable. En el caso estatal, fue a principios de los años noventa que se comenzó a apoyar la competitividad de las empresas locales, respaldada por el Programa Estatal de Impulso Industrial y Expansión a la Actividad Industrial 1992-1997; sin embargo, no fueron muchos sus alcances en la entidad.

Otra causa de esta escasa vinculación está muy relacionada con lo que señala Vázquez-Barquero (1999) cuando se refiere a que, todavía en los noventa, los actores económicos nativos jugaban un papel conservador y eran raros los casos en que los inversionistas se involucraban en proyectos 
de alto riesgo, como los industriales y tecnológicos, que demandan altos montos de capital y su recuperación normalmente es de largo plazo. ${ }^{5}$

Más tarde, en el año 2000, debido a la recesión que atravesaba la economía mundial, y en especial la estadounidense, muchas empresas del sector automotriz entraron en procesos de reestructuración global para reducir costos y enfrentar la sobreproducción y, por ende, el aumento de la competencia. La relocalización de sus inversiones fue otra vez una de las estrategias que utilizaron las trasnacionales automotrices en todo el mundo: se trasladaron de los países desarrollados a los que se encontraban en vías de desarrollo, con ello esperaban disminuir significativamente sus costos de producción.

Con respecto a lo anterior, destacan algunos casos de nuevas inversiones que las trasnacionales planeaban realizar entre 2003 y 2006, por ejemplo: las inversiones que harían Volkswagen en México, Brasil, China y Rusia; Nissan en México y España; Gm en Corea, México y China; Toyota en México y China; Mercedes Benz en China, y fMc quien invertiría en México, Tailandia y China. ${ }^{6}$ Con estos ejemplos se aprecia que China y México, en los últimos años, aparecían como alternativas atractivas para relocalizar sus inversiones (Wong, 2003).

\subsection{Ampliación de la planta. El nuevo proyecto Ford en Hermosillo}

La decisión de considerar a Hermosillo como el epicentro de toda una estrategia de FMC tuvo mucho que ver con que esta planta ha sido reconocida por instituciones de alto renombre, como el Massachusetts Institute of Technology, como la mejor planta automotriz en el mundo en términos de calidad, premio que le otorgó dicha institución en el año de 1991.

En 1991 la planta lanzó su segundo turno, aumentando su producción de 270 unidades diarias en 1986 a 700, y su planta productiva de 1,200 a 2,200 empleados. Fueron la calidad del producto de la planta, la mano de obra sonorense, los costos competitivos derivados de las ventajas fiscales y de la misma mano de obra, por lo que FMC se decidió por la plaza de Hermosillo (CEs, 2005).

\footnotetext{
${ }^{5}$ La falta de integración obedeció de alguna manera a la política estatal, pero también fueron altamente responsables, y lo siguen siendo, los empresarios locales que francamente tienen una muy alta aversión al riesgo y prefieren las inversiones seguras.

${ }^{6}$ Ejemplos concretos de esto fueron las inversiones en 2005 por parte de Nissan en su planta de Aguascalientes, por un valor superior a 1,300 millones de dólares para la fabricación del modelo Tiida y el aumento de la capacidad de exportación de dicha planta. También, la inversión realizada por Toyota en su planta en Tijuana en 2006, con el fin de incrementar la producción de la camioneta Tacoma. Finalmente, GM inició en 2006 la construcción de su cuarta planta en México, con una inversión superior a 2,000 millones de dólares.
} 
El 6 de octubre de 2003, el presidente de la República, el gobernador del estado de Sonora y directivos de FMC, como parte del nuevo proyecto, inauguraron las obras de construcción de la ampliación de la planta ensambladora en la ciudad de Hermosillo. Con ésta se incrementaría su capacidad productiva y se esperaba fuera un detonante tanto de la economía local como nacional, pues junto con la ampliación se programó la instalación en la ciudad de algunas de sus plantas proveedoras de primer y segundo niveles ${ }^{7}$ (Sandoval, 2005).

Este nuevo proyecto implicó una inversión de 1,200 millones de dólares por parte de FMC y 400 millones de dólares más por parte de los 16 proveedores de primer nivel que en un principio se instalarían en el estado, esperando conformar todo un conglomerado industrial con la finalidad de proveer a la planta terminal de todos los insumos necesarios para el ensamble y alimentación de sus tres líneas de producción.

Con dicha inversión se implementa una nueva plataforma, al pasar de plantas manufactureras satélites a todo un sistema de producción flexible, para integrar en Hermosillo el total del ensamble de una variedad de modelos basados en la demanda. Los tres modelos a producir eran: FordFusión, Lincoln-Zephry y Mercury-Milán, de los cuales se esperaba una producción anual de 305,000 unidades, destinando 95\% a la exportación (CEs, 2005; Islas, 2004).

Las condiciones en que se presentó este nuevo proyecto industrial en el estado fueron distintas a las de los años ochenta. Sin embargo, cuando se hizo el anuncio de dicho proyecto, la mayoría de los empresarios sonorenses todavía no estaban involucrados en las actividades industriales y mucho menos en las automotrices. Esto debido a diversos factores culturales, personales, tecnológicos y financieros.

A diferencia de los años ochenta, se tenía una mayor esperanza de que los empresarios locales participaran en alguno de los eslabones de la cadena, debido a que, por una parte, los actores locales como empresarios, asociaciones empresariales y organismos gubernamentales se empezaron a coordinar para aprovechar esta segunda oportunidad y, por otra, que el enfoque de los programas industriales federales y estatales había cambiado, ya que a partir del año 2000 se comenzaron a emitir programas que

${ }^{7}$ En la definición que hace Cubillo (2003) de proveedores de primer y segundo niveles, clasifica a los del primero en tres tipos, dependiendo del producto que suministran: $a$ ) los que se especializan en la producción de bienes intensivos en tecnología y que suministran a los ensambladores un producto o sistemas completos; $b$ ) los que se especializan en alguna tecnología de proceso, y $c$ ) los mayoristas que organizan a los proveedores de menor tamańo. En el caso de los proveedores de segundo nivel, los define como las empresas pequeñas y medianas que se especializan en componentes estandarizados, de reducida complejidad y tecnología madura, que cuentan con una escasa autonomía, dependiendo siempre de las necesidades de los proveedores de primer nivel. 
de manera específica buscaban apoyar al microempresario en cuanto a capacitación y financiamiento.

Entre las acciones que llevó a cabo el gobierno para realizar este proyecto estuvieron la promoción del estado y el apoyo en infraestructura y estímulos económicos. ${ }^{8}$ Con dichas acciones se buscó hacer de Hermosillo un lugar atractivo para que invirtieran tanto FMC como sus proveedores.

Para completar y confirmar la hipótesis era necesario conocer la opinión de los actores que intervinieron en el nuevo proyecto de FMC y cómo se están organizando para lograr un encadenamiento productivo en la industria automotriz de Sonora. En los siguientes apartados se describen los actores que participaron en la investigación (trabajo de campo), la metodología utilizada y los resultados obtenidos.

\section{Encadenamientos productivos en Sonora, metodología}

\subsection{Actores}

Después de revisar diversos artículos, así como los planes y programas emitidos por el gobierno del estado de Sonora, se ubicaron los actores principales en dos grupos. Por un lado, los organismos gubernamentales y asociaciones empresariales, quienes se encargan de emitir políticas y programas para apoyar tanto a las micro, pequeñas y medianas empresas (Mipyme) como a la gran empresa. Y por el otro, los proveedores actuales y potenciales (o microempresarios locales), quienes reciben los beneficios de dichas políticas y programas.

\subsubsection{Organismos gubernamentales y asociaciones empresariales (emisores)}

En cuanto a los organismos gubernamentales, se consideraron los que intervienen en la economía del estado, sobre todo en el sector industrial, ya fuera mediante la elaboración de políticas, aplicación de programas, promoción al estado o apoyando financieramente al empresario local. Para el caso de las asociaciones empresariales, se seleccionaron las que cuentan con agremiados tanto de la industria de transformación, como

\footnotetext{
${ }^{8} \mathrm{El}$ apoyo que ofrecieron los tres niveles de gobierno consistió en: exenciones de los derechos de conexión de servicios de agua potable y alcantarillado; exención del impuesto predial, en costos de licencia de construcción, permisos y registros; infraestructura, como la construcción de un crucero con desnivel en la inserción del Periférico Oriente y la carretera a la Colorada-Sahuaripa; una nueva vía de ferrocarril dentro del parque industrial; rápida emisión de trámites y permisos; ampliación del servicio de transporte; suministro suficiente de gas natural; instalación de una subestación eléctrica; construcción de puentes peatonales y ampliación de la carretera Hermosillo a la planta de FMC (Escalante, 2003).
} 


\section{Cuadro 3}

\section{Organismos gubernamentales y asociaciones empresariales}

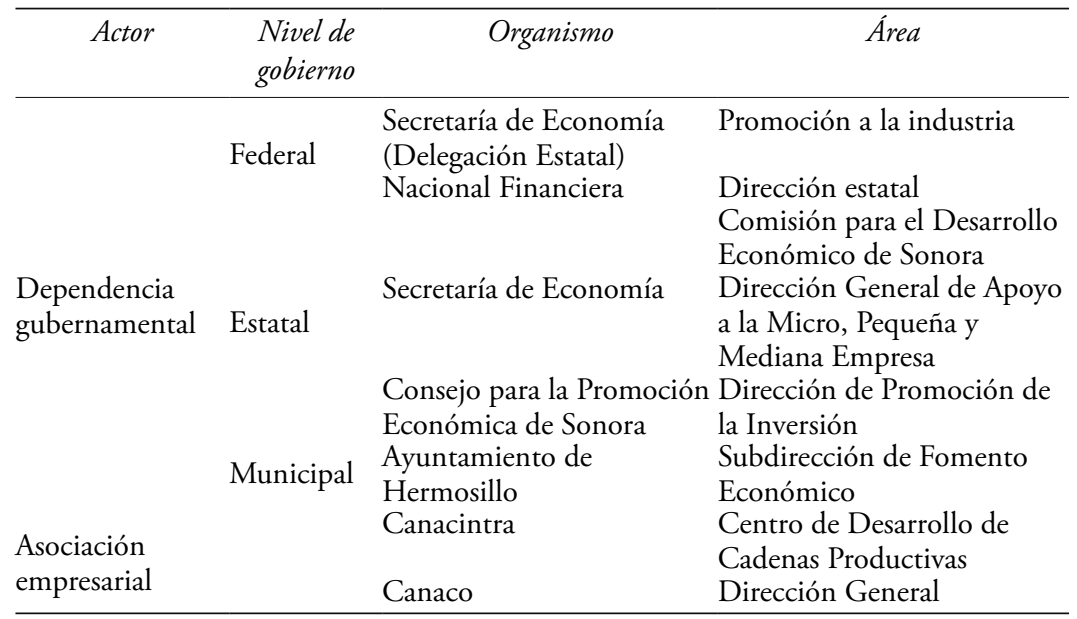

Fuente: Elaboración propia con información obtenida de los cuestionarios aplicados.

del sector comercio o servicios. En el cuadro 3 se describe específicamente este grupo de actores.

\subsubsection{Proveedores actuales y potenciales (receptores)}

Entre los receptores o beneficiarios de los programas y acciones se consideró a los proveedores de materia prima y servicios de FMC establecidos en el estado de Sonora, así como a microempresarios nativos que estuvieran interesados en participar en la cadena de proveduría de dicha trasnacional.

Para obtener la muestra de los proveedores a entrevistar, se elaboró un directorio con información recabada de revistas y presentaciones realizadas durante 2003 y 2004 por el personal de FMC, el Consejo para la Promoción Económica del Estado de Sonora (Copreson) y la Secretaría de Economía del Estado de Sonora. La información obtenida se corroboró posteriormente con funcionarios de dicha Secretaría y CanacintraHermosillo. Se obtuvo un universo de 27 proveedores, entre los que se encontraban de primero, segundo y cuarto niveles. ${ }^{9}$

De este total únicamente se contactaron seis proveedores, debido a que muchos de ellos se encontraban en el proceso de construcción de sus plantas o todavía no llegaban físicamente al estado; sin embargo, dicha muestra resultó suficiente debido a que sólo se pretendía conocer qué tanta relación tenían con los proveedores locales y su punto de vista sobre

\footnotetext{
${ }^{9}$ Los proveedores que pertenecen a este nivel son empresas de servicios, como papelerías, limpieza, transporte, alimentos preparados, guarderías, etcétera.
} 


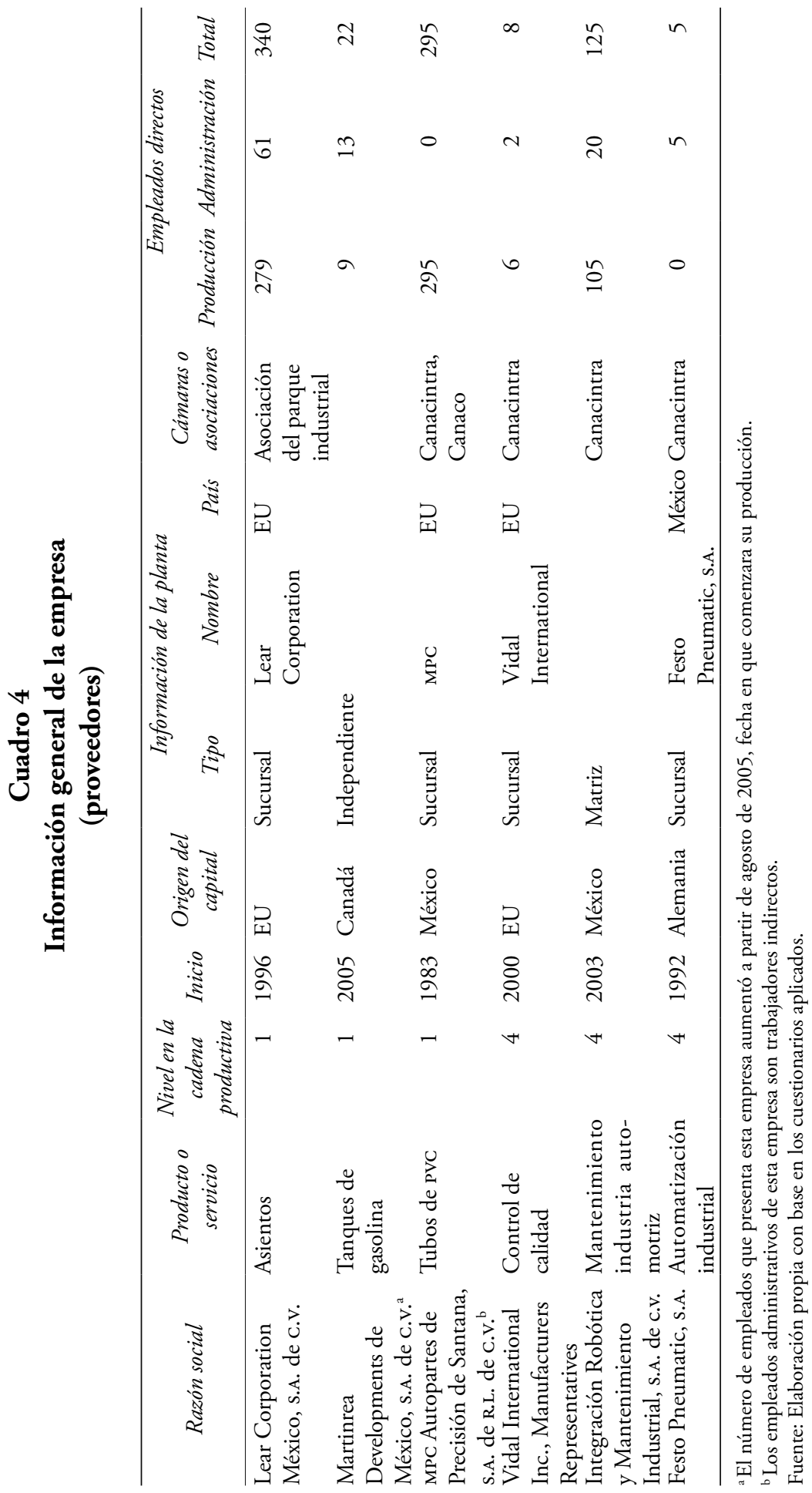


el apoyo que han recibido del gobierno, sus expectativas con respecto al nuevo proyecto y qué diferencias encontraban con lo que sucedió en los años ochenta. En el cuadro 4 se describen las características de cada uno de ellos.

Para el caso de los empresarios locales o proveedores potenciales, se contactó a tres microempresarios, que representan una muestra suficiente, ya que se quería conocer su punto de vista con respecto al apoyo que han recibido del gobierno y las asociaciones empresariales para sumarse a la cadena de proveedores de FMC, sus capacidades productivas, expectativas con el nuevo proyecto y diferencias con los años ochenta.

El contacto con los microempresarios se hizo por medio de uno de ellos, quien estuvo investigando cómo entrar de manera directa o indirecta como proveedor de FMC. Durante ese proceso se encontró con otros microempresarios que estaban en la misma situación, por lo que cuando se le contactó para aplicar el cuestionario, se le pidió proporcionara los datos de los otros microempresarios. En el cuadro 5 se presentan los datos de sus empresas.

\subsection{Herramientas de investigación}

La metodología que se utilizó para obtener la información necesaria y alcanzar los objetivos propuestos se basó en dos herramientas de investigación: entrevistas semiestructuradas y cuestionarios levantados en los primeros meses de 2005. El procesamiento de los datos obtenidos fue electrónico, para lo cual se utilizaron como apoyo los programas computacionales Access, Excel, Word y Ucinet6.

\subsubsection{Entrevistas semiestructuradas}

Se utilizó esta herramienta con funcionarios de los organismos gubernamentales y asociaciones empresariales, porque con ella se le daría mayor libertad al entrevistado de emitir sus opiniones y al mismo tiempo se obtendría información más amplia sobre los temas a investigar. Como señala Rojas (2003), esta técnica o herramienta se aplica a los informantes que dentro de una comunidad, por su posición y experiencia, poseen información relevante sobre el tema de investigación.

Debido a que fue una entrevista semiestructurada o dirigida, se elaboró una guía de preguntas que, como señala Pardinas (1969), ayudan a recabar información sobre experiencias, acontecimientos o problemas sociales. Para elaborar la guía de las entrevistas se utilizó como base la investigación realizada por López (2002) enfocada en las instituciones de fomento de proveedores en la ciudad de Tijuana. Partiendo de dicha base, 


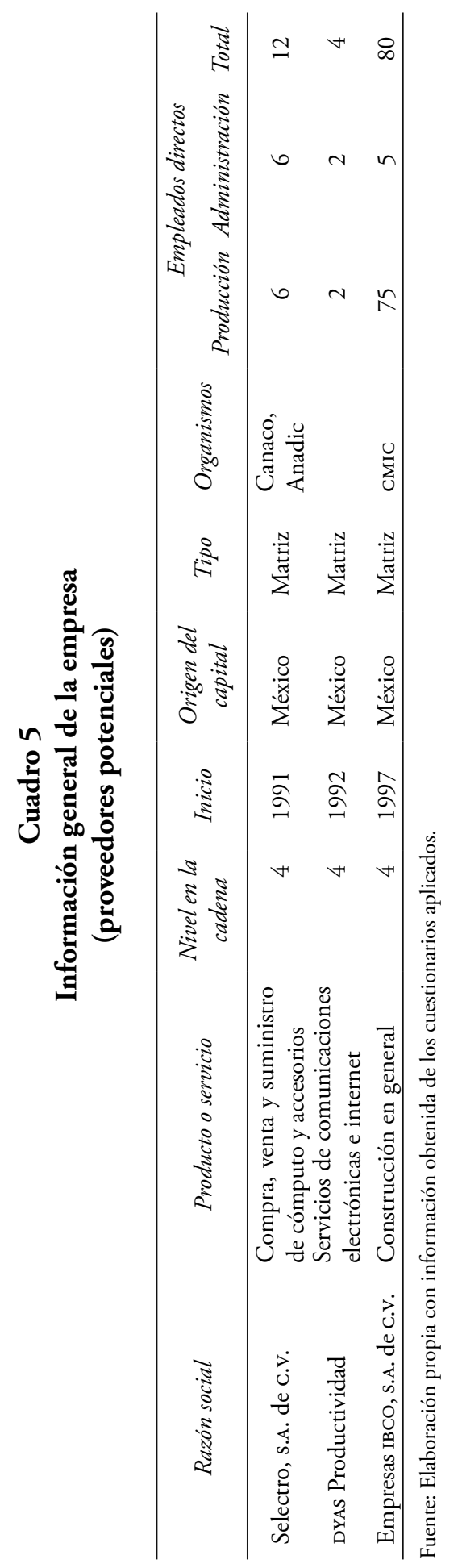


las preguntas se fueron adecuando a las necesidades del presente trabajo y también al organismo o asociación a entrevistar.

Los temas fundamentales a tratar en las entrevistas fueron: $a$ ) acciones que están llevando a cabo; $b$ ) su relación con otros organismos de gobierno y privados; $c$ ) cultura empresarial; $d$ ) diferencias que perciben entre esta época y los ańos ochenta cuando se instala FMC en Hermosillo, y $e$ ) las expectativas en cuanto al desarrollo de los empresarios y la economía locales.

\subsubsection{Cuestionarios}

Como complemento de la investigación se aplicaron cuestionarios a los proveedores actuales y potenciales. Para el proceso de diseño del cuestionario se utilizó como referencia la investigación que Lara (2004) realizó sobre encadenamientos productivos en las ciudades de Aguascalientes y Juárez.

Debido a la naturaleza de la información se utilizaron dos tipos de preguntas: cerradas, para obtener información de las empresas, como datos generales, su relación con clientes y proveedores y vinculación con organismos de gobierno y privados; y abiertas, para que de manera libre el entrevistado pudiera dar su punto de vista sobre sus expectativas del nuevo proyecto de Ford, las diferencias que encontraban con los años ochenta y algunas propuestas sobre políticas o programas necesarios para poder formar parte de la cadena de proveedores.

En el siguiente apartado se hace una descripción y se analizan los resultados obtenidos en las entrevistas sostenidas con los funcionarios de los organismos gubernamentales y asociaciones empresariales, así como de la aplicación de los cuestionarios a los proveedores actuales y potenciales.

\section{Nada nuevo bajo el sol...}

\subsection{Organismos gubernamentales y asociaciones empresariales}

Para que se dé un encadenamiento productivo en la industria automotriz del estado de Sonora es necesario que la formulación de sus políticas industriales la realicen el gobierno y los sectores productivos locales, ya que de esta manera, como señala Ruíz (2001), se podrán cubrir realmente las necesidades para lograr el desarrollo de los actores económicos del estado, es decir, los microempresarios o proveedores potenciales que se quieren sumar a la cadena de proveeduría.

Mediante las entrevistas se logró conocer cómo se relacionan los organismos gubernamentales y las asociaciones empresariales locales, así 
como las acciones llevadas a cabo para apoyar el desarrollo económico local. Por un lado, la promoción del estado para establecer nuevas inversiones nacionales y extranjeras, como la de FMC; y por el otro, cómo se estaba apoyando al empresario local para aumentar los niveles de competitividad que lo insertaran en la competencia global.

\subsubsection{Acciones}

En el caso del gobierno del estado de Sonora, las acciones que se llevan a cabo comienzan en Copreson, organismo que se encarga de promocionar al estado en los ámbitos nacional e internacional, para atraer inversiones a las áreas económicas donde se percibe mayor crecimiento y pueden ser motores de desarrollo, como automotriz, aeroespacial, metalmecánica, eléctrico-electrónico, textil, entre otras. Para lograr esas inversiones es necesario el apoyo de los tres niveles de gobierno y de los sectores productivos del estado, para crear una base sólida local en cuanto a mano de obra, infraestructura, proveedores, etcétera.

Las acciones continúan en la Comisión para el Desarrollo del Estado de Sonora, organismo que se encarga de ofrecer los incentivos fiscales y no fiscales a los inversionistas que se van a instalar en el estado. Otra de las funciones de dicha Comisión es conseguir recursos federales para que se canalicen a los programas productivos.

Estos dos organismos están dirigidos a apoyar o incentivar la instalación de la gran empresa que detone el desarrollo del sector industrial y, por consiguiente, de la economía local. Pero en la entrevista realizada se comentó que también han llegado a ellos microempresarios para solicitar apoyo y han sido canalizados a la Dirección General de Apoyo a la Micro, Pequeña y Mediana Empresa.

Esta Dirección es la que se encarga de impulsar la creación de Mipyme sonorenses nuevas y desarrollar a las que ya existen, pues como señaló en entrevista la Directora General, este sector económico es el que mayor peso tiene en el estado, por ello las acciones que realice la Secretaría de Economía del Estado de Sonora deben ser conjuntas con los empresarios locales para que se obtengan resultados que tengan un efecto real en la economía.

En el caso específico del nuevo proyecto de FMC de Hermosillo, esta Secretaría detectó que los proveedores que están siendo empleados por las compañías proveedoras son de servicios, por lo que la Dirección General busca apoyar primero a los proveedores de servicios industriales, y después promoverá el desarrollo de la Mipyme local dedicada al material productivo, para que suba niveles en la cadena de proveedores del sector automotriz. 
Para lograrlo, la Secretaría de Economía de Sonora, por medio de dicha Dirección General, bajó programas federales y está llevando acciones como el Programa de Desarrollo de Proveedores, para presentarlo a los proveedores de FMC que intervengan en el nuevo proyecto de la armadora en Hermosillo; el Programa de Incubación de Negocios, para el cual contrató la franquicia Empreser como apoyo en la parte de asesoría al microempresario; en lo que se refiere al financiamiento, el gobierno estatal cuenta con el Fondo para las Actividades Productivas del Estado de Sonora (FAPES), para acercarle al microempresario la oferta financiera pública y privada a la que pueden tener acceso.

Durante 2004 se firmaron convenios con el Comité Nacional de Productividad e Innovación Tecnológica, A.c. (Compite) y con el Centro Regional para la Competitividad Empresarial (Crece), estos dos para apoyo en asesorías técnicas, consultorías empresariales especializadas de calidad y certificación de ISO9001:2000, reingenierías de procesos, entre otros. En marzo de 2005 se firmó convenio con la Confederación Mexicana de Mejora Reguladora (Cofemer) para que el gobierno estatal fuera certificado en materia de mejora regulatoria y poder ofrecer el servicio del Centro de Apertura Rápida de Empresas (CARE).

También en 2005 se desarrolló un estudio financiado por la Fundación México-Estados Unidos para la Ciencia (Fumec), para conocer el efecto de las líneas de manufactura, es decir, en Sonora qué efecto indirecto tendrá la línea de manufactura del nuevo proyecto de FMC. El proyecto se denominó Estudio del impacto de las nuevas líneas de manufactura automotriz de la Ford en la región de Hermosillo, en el que colaboraron el gobierno del estado y centros de investigación, como El Colegio de Sonora y otros sectores económicos (Contreras, 2005).

En el corto plazo, la Dirección General buscará bajar otros programas al estado, como el Fundes, con el que dará capacitación y asesoría al empresario; también pretende crear con el Centro de Desarrollo de Cadenas Productivas de Canacintra-Hermosillo una bolsa estatal de subcontratación, que empezaría con recursos federales y estatales, pero al final se quedaría en el sector privado.

El Centro de Desarrollo de Cadenas Productivas fue una iniciativa que surgió a raíz del nuevo proyecto, la cual se presentó a la Secretaría de Economía del estado, quien interesada por apoyar al microempresario local respaldó dicha iniciativa y se puso en marcha en noviembre de 2004. Por tanto, el papel que desempeña Canacintra-Hermosillo también es importante, ya que en el Centro se está armando un esquema que sirva de enlace entre los proveedores actuales y los potenciales. Por un lado, recopila información acerca de las necesidades y especificaciones de los proveedores del sector automotriz que se están instalando en Sonora, y, 
por el otro, las necesidades de los empresarios locales en cuanto a apoyo financiero, asesoría y capacitación en sistemas de calidad o manufactura esbelta y certificación, para que tengan la capacidad de conectarse a la cadena de proveeduría.

En cuanto a las acciones que se están llevando a cabo en el ámbito federal, en la Delegación Estatal de la Secretaría de Economía, en específico en el área de Promoción a la Industria, al empresario local se le brindan servicios de trámites e información de los programas que ofrece dicha Secretaría. Por su parte, Nacional Financiera ha servido de apoyo a la Secretaría de Economía de Sonora y Canacintra-Hermosillo con cursos para capacitar al empresario local y sean sujetos de financiamiento.

En el ámbito municipal, la Subdirección de Fomento Económico -del ayuntamiento de Hermosillo- maneja los proyectos grandes del municipio, los promociona para atraer inversiones y ayuda con la gestión a las empresas establecidas o en vías de hacerlo en el municipio. En el nuevo proyecto de FMC ha apoyado sobre todo en la infraestructura, por ejemplo en el servicio de agua potable por medio de Agua de Hermosillo; y como gestores de manera informal de los proveedores de FMC.

Por último, la Canaco-Servytur de Hermosillo se encarga de informar a sus agremiados sobre los programas que se ofrecen en el estado para apoyarlos, pero en cuanto a los microempresarios que piensan insertarse en la cadena de proveeduría de la industria automotriz, los canaliza a la Secretaría de Economía estatal o a Canacintra-Hermosillo.

\subsubsection{Relaciones entre organismos gubernamentales y privados}

Aparte de los programas y acciones que se aplican para promocionar al estado y atraer grandes inversiones, así como para potenciar las capacidades productivas de las empresas locales, la investigación buscó conocer cómo se relacionan entre ellas.

Con la información que se obtuvo durante las entrevistas se armó una red de relaciones entre organismos gubernamentales y asociaciones empresariales, y también se ubicaron los organismos que apoyan al proveedor potencial para que llegue al proveedor de FMC.

Como se puede observar en el diagrama I, los actores centrales en la red fueron la Dirección General de Apoyo a Mipyme, el Centro de Desarrollo de Cadenas Productivas de Canacintra-Hermosillo y Copreson. En el caso de este último, que se encarga de promocionar al estado, recibe apoyo tanto de los tres niveles de gobierno como del sector empresarial, para que cuente con el respaldo en infraestructura (Ayuntamiento de Hermosillo), incentivos (Comisión para el Desarrollo de Sonora), programas de capacitación de recursos humanos y proveedores competitivos 


\section{Diagrama I \\ Relaciones entre organismos gubernamentales y privados}

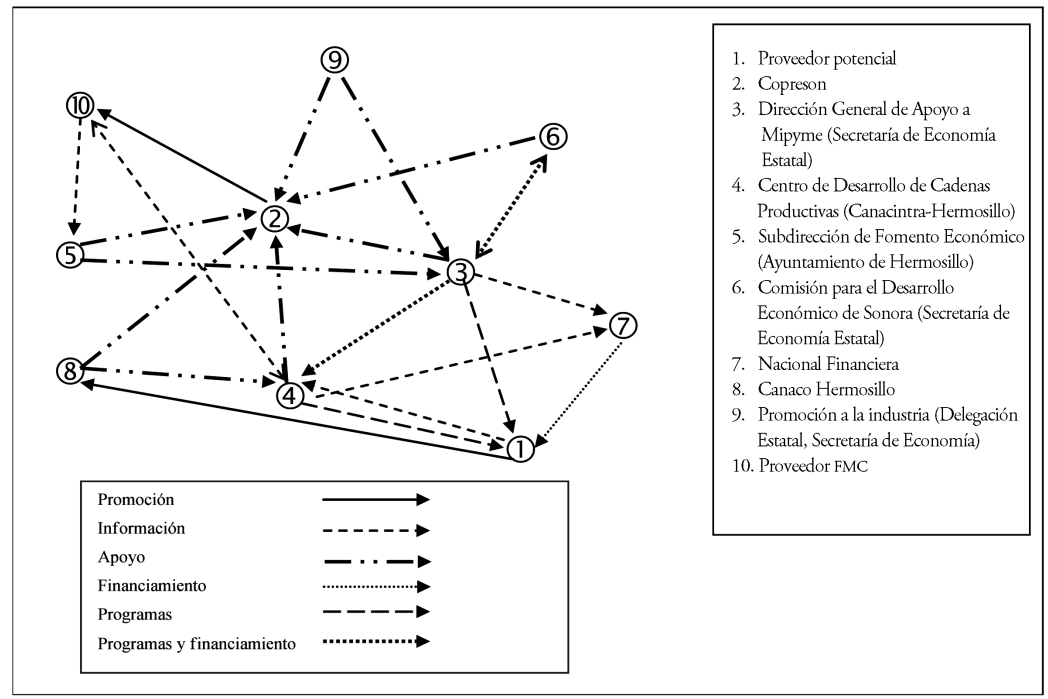

Fuente: Elaboración propia.

(Dirección General de Apoyo a Mipyme, Canaco, Canacintra), y establezcan sus inversiones en Sonora, como fue el caso de FMC y sus proveedores.

El Centro de Cadenas Productivas, que sirve como enlace entre los proveedores actuales y los potenciales, trabaja en conjunto con la Dirección General de Apoyo a la Mipyme para conseguir recursos y llevar a cabo programas con los cuales el empresario aumente su competitividad, se pueda certificar y conectarse a la cadena de proveedores. También recurre a Nacional Financiera para que le ofrezca al empresario cursos de capacitación empresarial y pueda obtener financiamiento.

La Dirección General de Apoyo a la Mipyme recibe apoyo federal para bajar al estado los programas con los que ayudará a su sector empresarial. Para conseguir los recursos para llevar a cabo dichos programas, se acerca a la Comisión para el Desarrollo Económico de Sonora, a quien le presenta las propuestas y ésta le facilita los recursos.

Por último, para que el proveedor potencial se relaciones con el proveedor, en principio tiene tres opciones. Cuando se trata de proveedores de servicios, generalmente recurren a la Canaco, pero en entrevista se comentó que, debido a que Canacintra-Hermosillo es quien está a cargo del programa de Cadenas Productivas, están dirigiendo a los empresarios hacia esta última; también pueden recurrir a la Dirección General de Apoyo a la Mipyme, quien en algunos casos les da respuesta o bien los canaliza a Canacintra-Hermosillo. 


\subsubsection{Cultura empresarial}

Para que se alcancen los objetivos propuestos por las políticas de fomento industrial existe un elemento importante: la participación del empresario local. En las entrevistas se abordó el tema de la cultura empresarial, para conocer cómo estos organismos perciben al empresario sonorense actualmente.

La idea general que se tuvo, de acuerdo con las respuestas, fue que a pesar de que se comienza a percibir una actitud de cambio en el empresario local, ésta no ha sido suficiente y, sobre todo, ha llegado demasiado tarde.

El paternalismo y la mentalidad de obtener ganancias en el corto plazo, la falta una cultura de riesgo y de más trabajo son algunas de las causas por las que el empresario no ha podido desarrollarse, sobre todo en el sector industrial. Los organismos también esperan que los empresarios tengan una actitud más proactiva, que de ellos salgan las iniciativas.

Por último, en cuanto a la calidad, señalaron que los empresarios no están acostumbrados a tener los niveles de competitividad y de calidad que está requiriendo la gran empresa, y algo muy importante, les falta mucha vocación de servicio.

\subsubsection{Diferencias con respecto a 1986}

Los entrevistados opinan que existen grandes diferencias entre lo que está ocurriendo con el nuevo proyecto y lo que sucedió en 1986, sobre todo consideran que ha habido avances en la infraestructura y servicios que se ofrecen en la ciudad de Hermosillo; valoran el proceso de cambio cultural que se está dando tanto en los ciudadanos como en los empresarios; el aumento en la oferta de servicios industriales y educativos; por último, recalcaron que lo más importante ha sido la modificación de la relación gobierno-iniciativa privada.

En relación con el último punto, en el ámbito gubernamental se percibe que en la actualidad, dado el cambio en dicha relación, los empresarios ya participan en las políticas económicas, existe retroalimentación de oportunidades y coordinación, lo que permite una mayor vinculación, por ejemplo con las universidades, pues con la información de la iniciativa privada se han creado nuevas carreras. ${ }^{10}$

Asimismo señalaron que el volumen de oportunidades se ha incrementado notablemente respecto de 1986, pues en ese entonces los em-

\footnotetext{
${ }^{10}$ La mayor parte de ellas en la Universidad de Sonora y en la Universidad Tecnológica de Hermosillo, ingenierías vinculadas a la producción industrial que elevarán en poco tiempo la calidad de la mano de obra local.
} 
presarios se enfocaban a proveerle sólo a Ford, sin considerar otras opciones, pero ahora, gracias a la instalación de nuevas empresas asociadas a la expansión de la planta, la visión del empresario se están dirigiendo a ellas, con el ánimo de tener un mercado diversificado.

Algo importante que señalaron fue que en los 20 años que tiene Ford instalada en el estado se ha tenido acceso a nuevas tecnologías y procesos productivos del sector automotriz, pero han sido muy pocos empresarios locales los que lo han aprovechado y logrado proveer materia prima al proceso productivo, lo que se refleja en una casi nula participación de insumos locales en el producto y por consiguiente un escaso encadenamiento productivo.

\subsubsection{Expectativas}

En cuanto a las expectativas, se hizo énfasis en la calidad. En el caso de la industria automotriz, se ha puesto mucha confianza en Hermosillo, por lo que el los gobiernos estatal y municipal, así como la comunidad tienen la responsabilidad de aumentar el nivel de calidad tanto del servicio como del producto. Por lo que el gobierno del estado espera que el empresario local desarrolle sus empresas, les den valor agregado y puedan solventar las necesidades especializadas de los proveedores que están llegando.

\subsection{Proveedores actuales y potenciales}

A los proveedores actuales y potenciales, como se señaló, se les aplicó un cuestionario para conocer por qué deciden instalarse en el estado, información sobre sus clientes y proveedores, su vinculación con los organismos gubernamentales y asociaciones empresariales; así como para que expresaran su punto de vista con respecto a sus expectativas ante el nuevo proyecto de FMC, las diferencias que encuentran con respecto a los años ochenta y recomendaciones para generar un encadenamiento productivo en el estado.

\subsubsection{Instalación en la ciudad y vinculos con la economia local}

De acuerdo con el cuadro 6, se puede confirmar que son las estrategias comerciales de cada empresa las que determinan su localización en algún punto del planeta, el caso de Sonora no es la excepción, ya que es una plaza que puede representar reducción de costos, por ejemplo en la localización geográfica, pues se encuentra en un punto que puede tener acceso rápido a otros países por su cercanía a la frontera con Estados Unidos, 


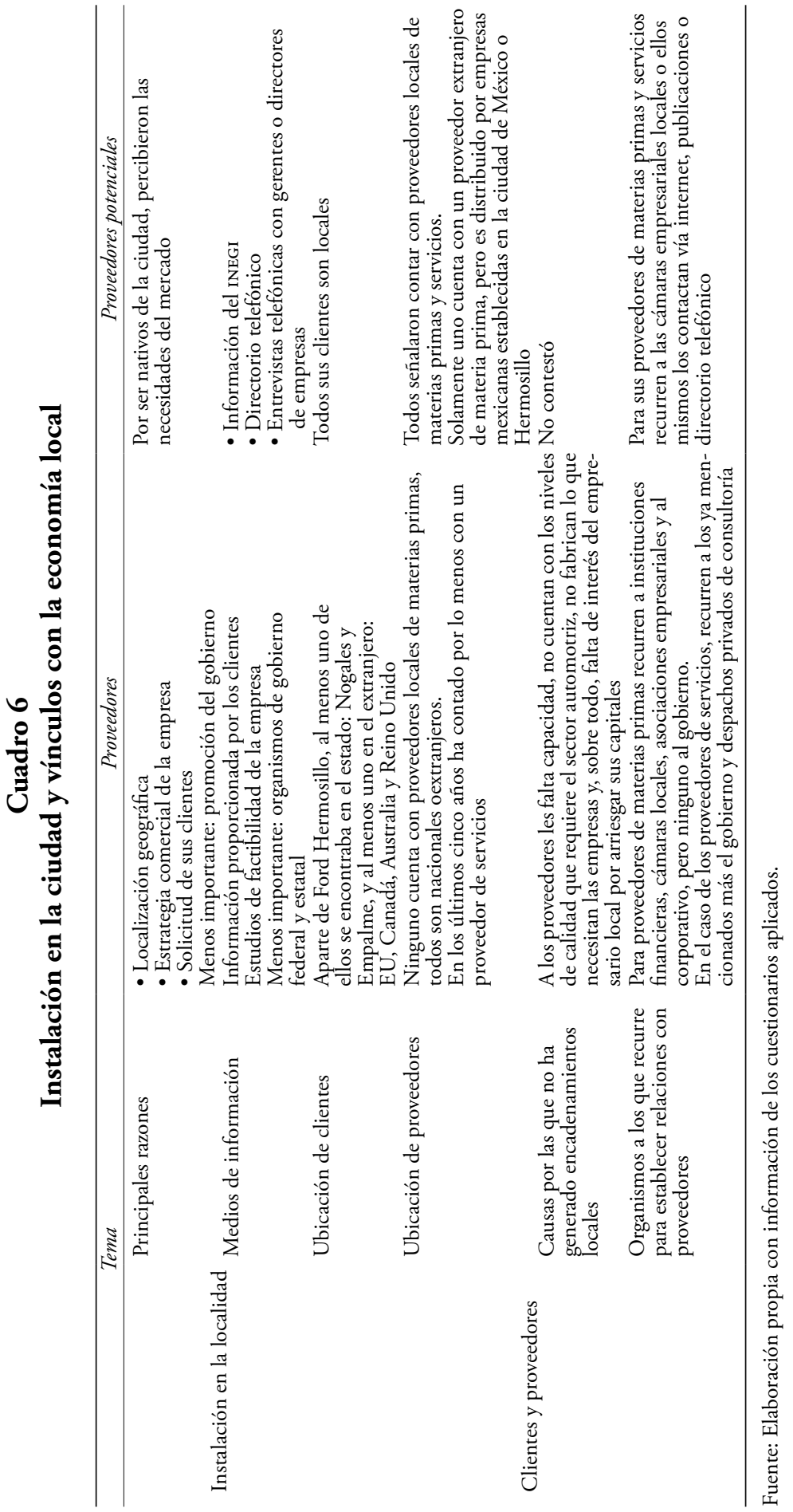


y un puerto de altura como el de la ciudad de Guaymas. La localización de las empresas de alta tecnología en el estado de Sonora no obedece a algún programa específico del gobierno, sino a sus propias estrategias de expansión.

Con respecto a la ubicación de sus clientes, se observa que en el caso de algunos proveedores su producción no depende exclusivamente de la demanda de Ford-Hermosillo, mencionaron tener al menos un cliente en el país o en el extranjero. En tanto que para los proveedores potenciales es evidente que sus capacidades no les han permitido abarcar más mercado que el local.

En el caso de la ubicación de sus proveedores, es claro que de parte de los proveedores de FMC no existe vínculo con proveedores de materia prima locales, lo que quiere decir que no hay encadenamiento productivo; sin embargo, han establecido vínculos con los proveedores de servicios.

Sobre por qué no se han vinculado con el proveedor productivo local, algunos contestaron haber tenido obstáculos para conformar encadenamientos productivos con proveedores locales, debido principalmente a la falta de interés por parte del empresariado local.

Para establecer relaciones con proveedores de materia prima, entre otros organismos recurren a las asociaciones o cámaras empresariales, lo que muestra que por ahí se podría comenzar a dar el enlace entre el proveedor productivo local y la gran empresa. Sólo han recurrido al gobierno para contratar proveedores de servicios.

\subsubsection{Coordinación con organismos gubernamentales y privados}

Acerca del apoyo que brindan los organismos gubernamentales y privados, tanto proveedores actuales como potenciales coinciden en que el ofrecido por las instituciones educativas es bueno, sobre todo para reclutar y capacitar a su mano de obra (cuadro 7). Para los proveedores potenciales, el apoyo que brindan las asociaciones empresariales es mejor que el del gobierno en sus tres niveles, esto debido a que muchas veces han recurrido a los organismos gubernamentales a solicitar información de los programas y han tenido muchos problemas para que los tomen en cuenta o le den seguimiento a sus casos, lo que ha generado en ellos cierta desconfianza en cuanto a la eficacia y veracidad de los apoyos que ofrecen.

En cuanto a las acciones llevadas a cabo por los organismos gubernamentales y privados que han influido en sus relaciones con proveedores o clientes, señalaron que los eventos organizados por las asociaciones empresariales y los seminarios, reuniones y ferias que organiza el gobierno, son los que mejor les han funcionado, debido a que en este tipo de eventos es donde logran tener contacto directo entre ellos. 


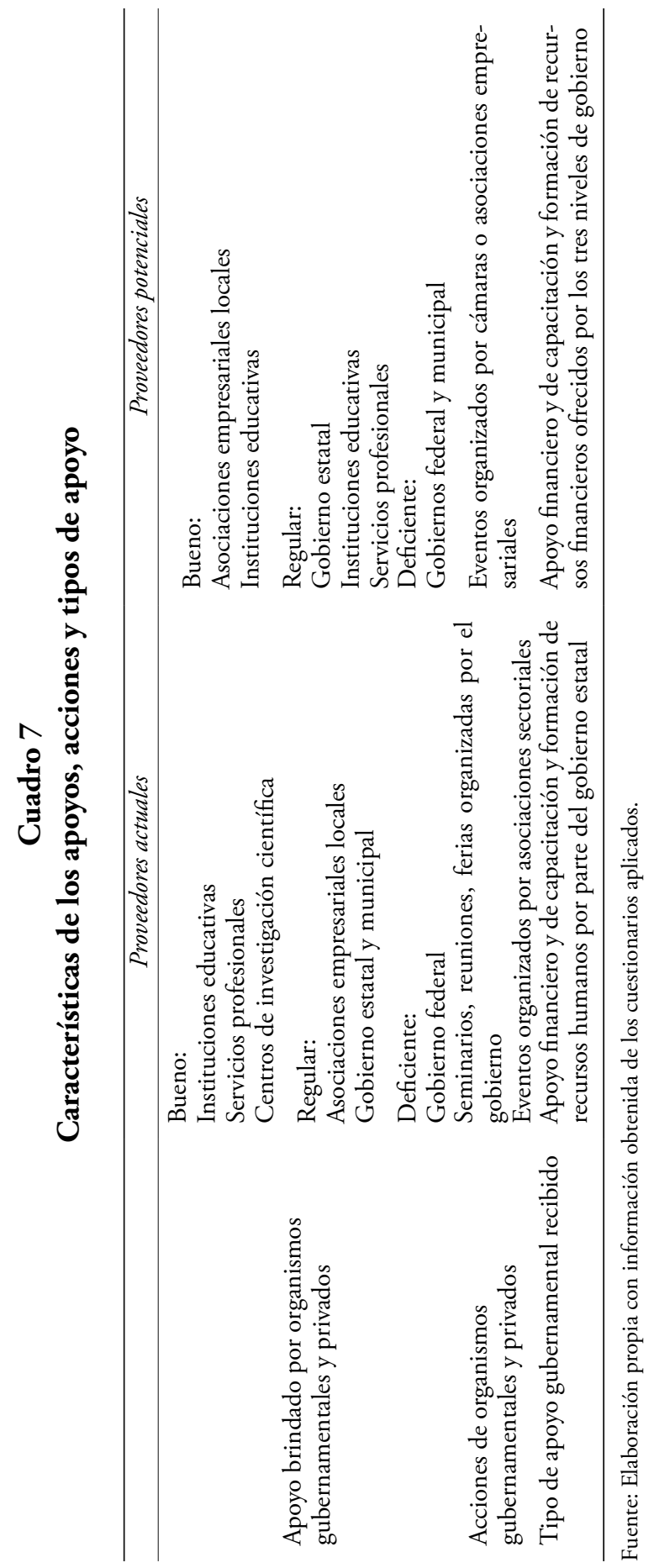


Por último, para conocer la difusión de los programas de fomento industrial ${ }^{11}$ que ofrece el gobierno en sus tres niveles, así como qué tanto se están aprovechando, en el cuestionario se les presentó una serie de programas relacionados con incentivos fiscales, apoyo tecnológico, innovación, calidad y fomento a la integración de empresas. Y por los resultados obtenidos se puede aseverar que la mayoría de los entrevistados no tenían conocimiento de ellos, al respecto uno de los proveedores potenciales señaló:

Mira, te voy a decir una cosa, yo creo que con muy poco temor a equivocarme, que todas las personas que ustedes han encuestado en esta situación, deben andar en el mismo rango de conocimiento de programas de gobiernos del estado o federales o municipales, entonces quiero decir con esto, que casi todo mundo los desconocemos.

\subsubsection{Expectativas ante el nuevo proyecto de FMC en Hermosillo}

En lo que se refiere a sus expectativas, se les preguntó acerca de lo que esperan de los proveedores locales, el apoyo del gobierno y la mano de obra. Para el caso de los proveedores locales comentaron que debido al arribo de muchas empresas foráneas, aumentará la competencia en el estado, lo que puede traducirse en que se estandaricen servicios y surjan nuevas opciones, se conformen alianzas entre proveedores locales para ofrecer mejor servicio, mayor calidad y buen precio; pero en lo que hicieron énfasis fue en que el empresario local debe cambiar todavía más su actitud, debe tener capacidad de compromiso, más arrojo y mejorar su calidad en el servicio.

Del gobierno esperan que los siga apoyando y que incentive el desarrollo de la tecnología local. También que esta vez haya mayor difusión de los programas y servicios que ofrecen, y que las acciones realizadas sean de largo plazo y tengan un efecto real en el desarrollo del empresario local.

Respecto a la mano de obra, señalaron que aunque saben que hay mano de obra capacitada y especializada, todavía no es suficiente, lo que en el mediano plazo se puede traducir en un déficit de mano de obra. Otro efecto que esperan los proveedores potenciales es en los salarios y prestaciones, pues debido a que son microempresarios difícilmente podrán ofrecer lo mismo que los grandes proveedores, por lo que corren el riesgo de que su personal se desplace a las nuevas empresas.

\footnotetext{
${ }^{11}$ Fueron 46 programas del ámbito federal y nueve del estatal. Dichos programas se seleccionaron del Programa de Desarrollo Empresarial 2001-2006, y se complementaron con información de la Secretaría de Economía del Estado de Sonora.
} 


\subsubsection{Diferencias con respecto a 1986, año en que se instala la planta Ford en Hermosillo}

Los entrevistados coincidieron en que existe un mejor conocimiento y mayor experiencia en el sector industrial, la mentalidad del sonorense está cambiando y tiende a ser más empresarial; la mano de obra ya está más capacitada y entrenada, y existe mayor relación entre empresa y gobierno. También señalaron que esperan un beneficio mayor, pues son más empresas las que se han instalado ahora que en aquella ocasión.

\subsubsection{Recomendaciones para generar un encadenamiento productivo en la región}

Por el lado de los proveedores, se sugirió crear un concepto integral de desarrollo del proveedor local, es decir, que no sólo se le apoye financieramente, sino que también lo capacite para que sea capaz de aprovechar los recursos. Que el gobierno se acerque más al gran empresario para que tenga conocimiento real de las necesidades tecnológicas y sobre ello trabajar para capacitar al proveedor, por ejemplo, con concursos estatales de creatividad tecnológica que ayuden a resolver los problemas locales.

Mientras tanto, los proveedores potenciales recomendaron que se institucionalicen programas como el Jueves Emprendedor; que las oportunidades que se generen en el estado se otorguen a empresarios locales y que desaparezcan los favoritismos, para que éstas realmente se les concedan a todos.

\section{Conclusiones}

A partir del proceso de globalización, en todo el mundo se ha desencadenado una serie de cambios estructurales en los ámbitos comercial, industrial y social. También a raíz de dicho proceso, las relaciones entre los países desarrollados y los que se encuentran en vías de desarrollo han cambiado y conforman redes económicas que influyen en el surgimiento de nuevos modelos de producción.

Hacer frente a estos cambios requiere formular políticas industriales eficientes, eficaces y efectivas. En México es a partir del periodo posrevolucionario cuando se empezó a considerar al sector industrial como motor de crecimiento. A partir de entonces se transformaron los patrones productivos del país: pasaron de una economía agrícola a una semiindustrializada. Fue en ese periodo que el gobierno comenzó a formular políticas de fomento industrial, las cuales se han transformando dependiendo de la coyuntura nacional e internacional. Desde los años cuarenta y hasta fina- 
les de los setenta, el gobierno intervino directamente en la economía y su política industrial tuvo un corte proteccionista basada en el MSI, que consiguió crecimiento económico pero sin lograr un desarrollo pleno de la industria nacional, se dejó de lado a las pequeñas y medianas empresas, no se incentivó la fabricación de bienes de capital y, al crear un mercado interno cautivo, se descuidaron los niveles de productividad y competitividad.

Más adelante, a principios de los noventa, debido al agotamiento del modelo proteccionista, se le dio un cambio estructural a la economía. La política económica se basó en la apertura comercial, y en materia industrial se fomentó la atracción de IED y la producción manufacturera dirigida a la exportación. Debido a la orientación de la política industrial, durante esta época se generó una dualidad en el desarrollo de la industria nacional, pues el financiamiento y la tecnología sólo estuvieron al alcance de unas cuantas empresas, generalmente de gran tamaño, las demás (las Mipymes) quedaron debilitadas por las medidas tomadas en el periodo proteccionista y tratando de soportar la competencia generada por la apertura comercial, por lo que al final muchas de ellas desaparecieron.

En este periodo, el estado de Sonora se incorporó al propósito nacional encaminado a fortalecer al sector exportador, atraer inversión extranjera, generar empleos y captar divisas. La década de los ochenta representó para la entidad el auge del crecimiento de su sector industrial, y para ello se aprovechó tanto el cambio estructural de la economía mexicana, como las transformaciones que en el ámbito internacional se estaban dando en los procesos productivos de las empresas mundiales y las relaciones comerciales entre países industrializados y los que estaban en vías de desarrollo, éstas fueron clave para la instalación de empresas trasnacionales en territorio sonorense. Fue cuando se presentó FMC como una alternativa viable para lograr los propósitos nacionales y estatales.

Prácticamente, el inicio de la industria automotriz en el estado de Sonora se dio en 1984, cuando FMC anunció que instalaría una planta de estampado y ensamble en la ciudad de Hermosillo y posteriormente su puesta en marcha en 1986. La instalación de dicha planta en la entidad respondió, en mayor medida, a las necesidades de la trasnacional por reducir costos, aumentar utilidades y afrontar la competencia que se estaba dando en la industria automotriz de Estados Unidos, por lo que implementó nuevos modos de organización, producción y localización.

Esto representó para la economía del estado una oportunidad para desarrollar una base industrial y tecnológica enfocada en la industria automotriz. Pero lamentablemente la industria local, al igual que la nacional, presentaba rezagos tecnológicos y de competitividad, primero por la política proteccionista que duró hasta finales de los años setenta y 
después por la falta de apoyo durante la apertura comercial, aspectos que la marginaron del desarrollo.

Por lo anterior, en los años noventa el gobierno dirigió su mirada hacia las Mipymes locales, comenzó a crear políticas industriales que retomaron conceptos como competitividad y productividad, empezaron a dar importancia al fomento de cadenas productivas y agrupaciones industriales (clusters), así como mayor libertad a los gobiernos estatales y municipales para participar en la elaboración de programas industriales. En el caso de Sonora, ha sido difícil integrar las Mipymes locales a los grandes proyectos industriales, como los de la industria automotriz. Durante muchos años, el gobierno local se centró en atraer inversión extranjera y dejó de lado a este sector económico, lo cual se reflejó en su escasa participación en los productos finales.

Casi 20 años después de la instalación de la planta automotriz, a la economía sonorense se le presentó una nueva oportunidad, con el anuncio de que FMC ampliaba su planta de Hermosillo y con ello intervendrían nuevos proveedores que se instalarían en la ciudad. A raíz de dicha noticia, los actores económicos locales comenzaron a organizarse para aprovechar la coyuntura y conformar un encadenamiento productivo alrededor de la industria automotriz.

Desafortunadamente, los resultados de esta investigación apuntan que en Sonora no se ha logrado generar un encadenamiento productivo alrededor de la industria automotriz, debido a que las políticas y acciones de los organismos gubernamentales no han sido suficientes para apoyar el desarrollo de las capacidades productivas del empresario.

En lo que se refiere a las políticas de fomento industrial, durante muchos años estuvieron enfocadas a crear las condiciones en el estado para la instalación de la gran empresa nacional o extranjera dedicada a la exportación, dejando de lado las necesidades de los empresarios locales o proveedores potenciales para que pudieran vincularse con la gran empresa en sus procesos productivos.

Al respecto, es importante señalar que conforme se fue realizando la revisión de Planes de Desarrollo y Programas Industriales, en los ámbitos federal y estatal, se pudo observar que sexenio tras sexenio se proponían objetivos similares, dirigidos a apoyar la industria nacional y local, lo que puede confirmar que por muchos años las propuestas no llegaron a los empresarios locales, lo cual se reflejó en la baja participación de insumos de fabricación nacional en los productos finales que se dirigían a la exportación.

En cuanto a las acciones, y con base en los resultados obtenidos de las entrevistas, se pudo confirmar que en los ańos ochenta, a pesar de que el sector empresarial comenzaba a participar junto con el gobierno en la 
formulación de políticas industriales, no lograron organizarse para que en conjunto apoyaran el desarrollo de las Mipymes.

Otra causa importante ha sido el interés de parte del empresario sonorense por invertir en el sector industrial, y en específico en el automotriz. La cultura empresarial por muchos años ha sido la de invertir en sectores económicos de bajo riesgo y en los que puedan obtener ganancias en el corto plazo, como son el agropecuario y de servicios. Es únicamente en este último sector donde el microempresario local ha podido formar parte del grupo de proveedores de las empresas del sector automotriz del estado.

Actualmente se intenta lo que no se ha logrado en décadas: conformar encadenamientos productivos. Los actores económicos locales, tanto públicos como privados, se están organizando para diseñar una nueva política industrial que apoye e impulse al empresario local para insertarse en las cadenas productivas de los nuevos proyectos del estado y, en especial, el automotriz en la ciudad de Hermosillo.

Varios son los factores importantes que intervendrán en este nuevo desarrollo, entre ellos el corte de las políticas industriales, el cual ahora es más descentralizado y permite al gobierno estatal tomar decisiones independientemente de las federales, lo que puede traducirse en que las políticas ayuden realmente al desarrollo regional, ya que serán más específicas y atenderán de manera más directa las necesidades de los empresarios sonorenses, pues la relación entre sector privado y gobierno ha cambiado al hacer partícipe al empresario en la formulación de programas y políticas.

Aun cuando hay un nuevo enfoque en las políticas y acciones de parte de los organismos gubernamentales, éstas todavía no han logrado llegar hasta el microempresario, lo que se refleja en el bajo número de microempresarios o proveedores potenciales que se han acercado a solicitar los servicios y programas de apoyo que ofrece el gobierno del estado, en gran parte también porque todavía existe entre ellos cierta desconfianza en que el apoyo de los organismos gubernamentales sea válido y funcional.

El acercamiento de los microempresarios se ha dado más por el lado de las asociaciones empresariales, como Canacintra-Hermosillo, pues es ahí donde, a raíz del anuncio del nuevo proyecto de FMC, se propuso crear un Centro de Desarrollo de Cadenas Productivas, el cual está realizando el enlace entre los proveedores de FMC y los proveedores potenciales.

También en el plano de acción pública, y a partir de los resultados de la investigación, se recomienda implementar amplias campañas para difundir los programas y servicios que ofrecen los organismos gubernamentales y privados que están interviniendo en este nuevo proyecto, pues sólo de esta manera podrán llegar hasta el proveedor potencial. Asimismo, se recomienda que el apoyo que se empieza a brindar a los microempresarios 
sonorenses sea real y efectivo, y se dé seguimiento a los casos particulares hasta que logren conectarse en la cadena de proveedores de materia prima de la industria automotriz del estado.

El fomento a las cadenas productivas debe ser real y evitar la simulación, además es necesario que el apoyo sea transparente y se canalice a aquellos empresarios locales que lo necesitan para elevar sus niveles de competitividad y puedan participar en el proceso productivo de la industria automotriz.

No menos importante que lo anterior es que los empresarios cambien su actitud y superen su posición paternalista, se debe reconocer que no todo tiene que ver con las acciones gubernamentales, una buena parte de la incapacidad para integrarse a la cadena productiva se encuentra en la actitud de los empresarios, los cuales tienen aversión al riesgo y apuestan poco a proyectos innovadores.

\section{Bibliografía}

Carrillo, Jorge (1990), "Maquilización de la industria automotriz en México. De la industria terminal a la industria del ensamble", en Jorge Carrillo (coord.), La nueva era de la industria automotriz en México, El Colegio de la Frontera Norte, Tijuana, pp. 67-114.

Carrillo, Jorge (1997), "Maquiladoras automotrices en México: clusters y competencias de alto nivel", en Martha Novick y María Gallart (comps.), Competitividad, redes productivas y competencia laboral, Organización Internacional del Trabajo-Cintefor-Red Educación y Trabajo, Montevideo, pp. 193-234.

Carrillo, José (2003), "Expectativas municipales e infraestructura y servicios", ponencia presentada en el seminario estatal Impactos de la expansión de la planta Ford en Sonora, El Colegio de SonoraCentro de Investigación en Investigación y Desarrollo, Hermosillo, 5 de noviembre.

CES (Comercio Exterior Sonorense) (2005), "Presencia de la industria automotriz en Sonora desde 1986”, 123, ces, Hermosillo, pp. $10-11$.

Contreras-Montellano, Óscar Fernando (coord.) (2005), "Estudio sobre el impacto de la ampliación de la Ford Motor Co. en Hermosillo, Sonora”, Fundación México-Estados Unidos para la Ciencia-El Colegio de Sonora, Hermosillo. 
Cubillo, José María (2003), "Implicaciones territoriales de la inversión extranjera", Comercio Exterior, 3, Banco Nacional de Comercio Exterior, México, pp. 244-255.

Escalante, Ignacio (2003), "Impacto en la economía regional”, ponencia presentada en el foro de análisis La ampliación de la planta Ford Hermosillo", El Colegio de Sonora, Hermosillo, 29 de octubre.

Fimbres, Raúl (1984), "Viabilidad social y económica para el establecimiento de una planta ensambladora en Hermosillo Sonora (Ford de México)", tesis de licenciatura, Universidad Nacional Autónoma de México, México.

Gereffi, Gary (1995), "Global production systems and third world development", en Barbara Satalling (ed.), Global change, regional response: the new international context of development, Cambridge University Press, Nueva York, pp. 100-142.

Gereffi, Gary (2002), “Globalización, cadenas productivas y pasaje de naciones a eslabonamientos superiores. El caso de la industria del vestido", en Jorge Basave et al. (coords.), Globalización y alternativas incluyentes para el siglo XXI, Miguel Ángel Porrúa, México.

Gereffi, Gary, Miguel Korzeniewcz y Roberto Korzeniewicz (1994), “Introduction: global commodity chains", en Gary Gereffi y Miguel Korzeniewicz (eds.), Commodity chains and global capitalism, Praeger, Connecticut, pp. 1-15.

Islas, José (2004), "Proyecto Ford: impulsor del desarrollo de Sonora", ponencia presentada en la ir Semana Cultural de la División de Ingeniería, Ingeniería Industrial y de Sistemas, Universidad de Sonora, Hermosillo, 8-12 de noviembre.

Lara, Blanca (2004), "Encadenamientos productivos y promoción industrial en dos conglomerados automotrices. Un acercamiento a las experiencias de Aguascalientes y Juárez (1990-2002)", tesis de doctorado, El Colegio de la Frontera Norte, Tijuana.

López, María del Rosario (2002), "Las instituciones de fomento de proveedores en la industria electrónica como alternativa de desarrollo industrial en Tijuana, B.C.", tesis de maestría, El Colegio de la Frontera Norte, Tijuana. 
Maldonado, Serafín (1995), "La rama automovilística y los corredores industriales en el noroeste de México", Comercio Exterior, 6, Banco Nacional de Comercio Exterior, México, pp. 487-497.

Pardinas, Felipe (1969), Metodología y técnicas de investigación en ciencias sociales, Siglo XXI, México.

PeF (Poder Ejecutivo Federal) (1983), Plan Nacional de Desarrollo 19831988, Secretaría de Programación y Presupuesto, México.

Porter, Michael (1991), La ventaja competitiva de las naciones, Vergara, Buenos Aires.

Ramírez, José y Bernardo González-Aréchiga (1993), "Reestructuración y apertura del sector automotriz en México", Investigación Económica, 204, Universidad Nacional Autónoma de México, México, pp. 71-112.

Rojas, Raúl (2003), Guía para realizar investigaciones sociales, Plaza y Valdés, México.

Ruíz, Clemente (2001), "Descentralización de la promoción económica”, El Mercado de Valores, 10, Nacional Financiera, México, pp. 4-11.

Sandoval, Sergio (1987), "Los enlaces económicos y políticos de la Ford Motor Company en Hermosillo. Internacionalización productiva y nuevas tecnologías", tesis de maestría, El Colegio de Sonora, Hermosillo.

Sandoval, Sergio (2003), "Hibridación social: un modelo conceptual para el análisis de la región y el territorio", Región y Sociedad, 28, El Colegio de Sonora, Hermosillo, pp. 47-80.

Sandoval, Sergio (2005), "Modernización reflexiva y trabajo en la planta de Ford Hermosillo: un modelo para reflexionar el nuevo proyecto de expansión”, Imaginales. Revista de Investigación Social, 1, Universidad de Sonora, Hermosillo, pp. 133-151.

Secofi (Secretaría de Comercio y Fomento Industrial) (1984), "Programa Nacional de Fomento Industrial y Comercio Exterior 19841988", <http://www.legatek.com/dofhist/pub/>, abril de 2005. 
Vázquez, Miguel Ángel y María del Carmen Hernández (2008), “Industrialización sonorense. Itinerario de un proyecto inconcluso", Estudios Sociales. Revista de Investigación Científica, 31, Centro de Investigación en Alimentación y Desarrollo, Hermosillo, pp. 205-236.

Vázquez-Barquero, Antonio (2002), "El desarrollo endógeno, respuesta de las comunidades locales a los desafíos de la globalización", en Jorge Basave et al. (coords.), Globalización y alternativas incluyentes para el siglo XXI, Miguel Ángel Porrúa, México.

Vicencio, Arturo (2007), "La industria automotriz en México. Antecedentes, situación actual y perspectivas", Contaduría y Administración, 221, Universidad Nacional Autónoma de México, México, pp. 211-248.

Wong, Pablo (1999), "Globalización e integración productiva. El nuevo papel de los gobiernos locales y regionales", en Blanca Lara, Cristina Taddei y Jorge Taddei (comps.), Globalización, industria e integración productiva en Sonora, El Colegio de Sonora-Universidad de Sonora-Centro de Investigación en Investigación y Desarrollo, Hermosillo.

Wong, Pablo (2003), "Hermosillo en la estrategia global de Ford Motor Company", ponencia presentada en el seminario estatal Impactos de la expansión de la planta Ford en Sonora, El Colegio de Sonora-Centro de Investigación en Investigación y Desarrollo, Hermosillo, 5 de noviembre.

Ybarra, Josep-Antoni et al. (1998), "Distrito industrial y política industrial: el caso de la cerámica española", Investigación Económica, 223, Universidad Nacional Autónoma de México, México, pp. 47-76.

Zapata, Francisco (2005), Tiempos neoliberales en México, El Colegio de México, México.

Recibido: 19 de agosto de 2008. Reenviado: 24 de marzo de 2010. Aceptado: 18 de mayo de 2010. 
Fabiola Galicia Bretón-Mora. Es estudiante del octavo semestre y candidata a doctora en ciencias sociales, con especialidad en estudios regionales, por El Colegio de la Frontera Norte. Es maestra en Ciencias Sociales por el Colegio de Sonora, licenciada en economía por la Universidad Nacional Autónoma de México. Sus líneas de investigación actuales son industria y migración.

Isaac Leobardo Sánchez-Juárez. Es estudiante del octavo semestre y candidato a doctor en ciencias sociales, con especialidad en estudios regionales, por El Colegio de la Frontera Norte; es maestro en economía regional por el Centro de Investigaciones Socioeconómicas de la Universidad Autónoma de Coahuila; licenciado en economía por la Universidad Autónoma Benito Juárez de Oaxaca; diplomado en gestión estratégica del desarrollo local por el ILPES-CEPAL. Es profesor de la Escuela de Economía de la Universidad Autónoma Benito Juárez de Oaxaca. Sus líneas de investigación son: libertad económica, industrialización, crecimiento económico y desarrollo. Entre sus publicaciones destacan: "Crecimiento económico regional en México y políticas públicas, 1993-2006”, Observatorio de la Economía Latinoamericana, 84, Eumed, Málaga, pp. 1-23 (2007); "México: dos décadas perdidas", Revista Fortuna, Negocios y Finanzas, 66, Contralínea, México, pp. 10-12 (2008); “Teoría del crecimiento económico y divergencia regional en México", Entelequia, 9, Eumed, Málaga, pp. 129-149 (2009). 